\title{
Decoration supplementation and male-male competition in the great bowerbird (Ptilonorhynchus nuchalis): a test of the social control hypothesis
}

\author{
Natalie R. Doerr
}

Received: 16 March 2010/Revised: 23 May 2010/Accepted: 25 May 2010 /Published online: 12 June 2010

(C) The Author(s) 2010. This article is published with open access at Springerlink.com

\begin{abstract}
Many animals use signals to communicate their social status to conspecifics, and the social control hypothesis suggests that social interactions maintain the evolutionary stability of status signals: low-quality individuals signal at a low level to prevent high-quality individuals from "punishing" them. I examined whether the numbers of decorations at bowers are socially controlled in the great bowerbird (Ptilonorhynchus nuchalis). In two populations, I supplemented males with decorations to determine whether they (a) rejected supplemental decorations and (b) experienced increased bower destruction from rivals. In contrast to the social control hypothesis, males in both populations accepted most supplemental decorations. Though the mean destruction rate did not increase during supplementation in either population, one of the study populations (Townsville) exhibited a negative correlation between the numbers of decorations naturally displayed at bowers and the change in destruction rate during the experiment. Townsville males that naturally had few decorations at their bowers also had more decorations stolen by other males during supplementation than males that naturally had many decorations. These results suggest that the numbers of decorations at bowers are an honest signal of the male's ability to defend his display site from rivals in at least one population of the great bowerbird (Townsville), but they do not support the social control hypothesis because males at both sites failed to limit signal expression. I discuss how the external nature of bower decorations and their availability in the environment may
\end{abstract}

Communicated by M. Hauber

N. R. Doerr $(\bowtie)$

Department of Ecology, Evolution and Marine Biology,

University of California, Santa Barbara,

Santa Barbara, CA 93107, USA

e-mail: doerr@lifesci.ucsb.edu influence the costs and benefits of decoration theft and social control.

Keywords Extended phenotype - Great bowerbird . Honest signal $\cdot$ Male-male competition . Ptilonorhynchus nuchalis $\cdot$ Status signal

\section{Introduction}

Many animals use signals to communicate their social status to conspecifics (Fugle et al. 1984; Senar and Camerino 1998; Molles and Vehrencamp 2001; Martín et al. 2007), and these signals may allow individuals to perceive each other's status while avoiding costly fights (Rohwer 1975). Many status signals appear inexpensive to produce (Horn et al. 1995), and the social control hypothesis suggests that social interactions maintain the evolutionary stability of status signals (Rohwer 1977; Maynard Smith and Harper 1988; Tibbetts and Dale 2004). Cheating is limited because signalers often test one another, and subordinates that exaggerate their status become involved in costly fights they cannot win. Thus, social control ensures honest signaling because low-quality individuals signal at a low level to prevent high-quality individuals from "punishing" them. Originally formulated to explain plumage variation in flocks of wintering birds (Rohwer 1977), the social control hypothesis may also explain honest signaling in a mating context. In three-spined sticklebacks (Gasterosteus aculeatus) and red junglefowl (Gallus gallus), males reduce their signal expression when in the presence of superior competitors (Candolin 2000; Parker and Ligon 2007), and this may allow females to identify high-quality mates. Because the social control hypothesis suggests that social interactions can contribute to honest sexual signaling, this hypothesis is 
similar to indicator models (Zahavi 1975) in which the evolutionary stability of honest mating signals is maintained by the costs of producing or maintaining them.

Bowerbirds (Ptilonorhynchidae) are a unique system for studies of the social control of mating signals. Males of most species build and decorate stick structures, called bowers, to attract the females with whom they mate. Females prefer to mate with males that own well-decorated and wellconstructed bowers (Borgia 1985; Uy and Borgia 2000; Madden 2003; Coleman et al. 2004), though other male and bower characteristics may also influence female choice (Loffredo and Borgia 1986; Coleman et al. 2004; Robson et al. 2005). Because bower decorations are external to the birds, males can rapidly change the size of their mating signals, and in Spotted Bowerbirds (Ptilonorhynchus maculatus), low-quality males reject decorations added to their bowers, most likely to prevent rivals from destroying their bowers completely (Madden 2002). Because low-quality males reduced their signal expression to prevent "punishment" from rivals, these results suggest that social control facilitates honest sexual signaling.

However, the honesty of male mating signals in bowerbirds could also be influenced by a different form of malemale competition: decoration theft. In satin bowerbirds (Ptilonorhynchus violaceus), there was a positive correlation between the number of decorations at a male's bower and the number of decorations he stole from other males (Borgia and Gore 1986; Wojcieszek et al. 2007), and in great bowerbirds (Ptilonorhynchus nuchalis), the number of decorations at a male's bower was related to the male's ability to prevent theft from his own bower (Doerr 2010). Thus, honest sexual signaling may result from direct competition over resources (decoration theft hypothesis) rather than from a male's signaling restraint (social control hypothesis). Additional studies are needed in a single species to quantify the relative importance of decoration theft and socially controlled signals and to identify the environmental conditions that may favor one form of malemale competition over another.

In this study, I examined whether the numbers of decorations at bowers are socially controlled in the great bowerbird. First, I supplemented males with decorations to determine whether they rejected supplemental decorations. If the numbers of decorations at bowers are socially controlled, then males should reject most decorations added to their bowers, and there should be a positive correlation between the numbers of decorations at bowers before and after supplementation. Next, I supplemented males with decorations to determine whether they experienced increased bower destruction from rivals. If decoration numbers are socially controlled, then bower destruction should increase during supplementation, and males that naturally have few decorations should experience a greater increase in destruction rate when supplemented than males that naturally have many decorations. Because a previous study suggests that decoration theft may facilitate honest signaling in this species (Doerr 2010), I also documented the occurrence of decoration theft and examined how this affects the interpretation that decoration numbers at bowers are socially controlled. Finally, I conducted these experiments in two populations, one in which objects of potential use as decorations were relatively common in the environment and one in which they were relatively rare, so I also discuss whether environmental conditions may favor one form of male-male competition over another.

\section{Methods}

Study site and species

Great bowerbirds live throughout northern Australia and build one of the largest bowers of the Australian bowerbird species (average dimensions: $61 \times 51 \times 37 \mathrm{~cm}$; Frith et al. 1996). Males decorate bowers with hundreds of objects, including stones, shells, fruit, and human-made objects. Rates of decoration theft $(0.38 \pm 0.34$, mean and SD, decorations stolen per day; Doerr 2009b) and bower destruction $(0.6 \pm 1.3$, mean and $\mathrm{SD}$, minutes of destruction a bower experienced per day; N.R. Doerr, unpublished data) are similar to those recorded in other bowerbird species (reviewed in Frith and Frith 2004). Males build bowers between June and September, and most copulations occur between September and December (Frith et al. 1996; Frith and Frith 2004).

I conducted field work at two sites in northern Queensland, Australia: Townsville City $\left(19^{\circ} 19^{\prime} \mathrm{S}, 146^{\circ} 46^{\prime} \mathrm{E}\right)$ and Dreghorn Station $\left(20^{\circ} 15^{\prime} \mathrm{S}, 146^{\circ} 42^{\prime} \mathrm{E}\right)$. The habitat in Townsville consists of human-made gardens and eucalyptus woodland, and bowers were located at the Lavarack Barracks military base. Dreghorn station is a cattle property along the Burdekin River. Bowers were located in open eucalyptus woodland along Six Mile Creek and the Burdekin River (see Doerr 2009b for site maps). Bowers in Townsville contain more decorations $(1,090 \pm 591$; mean and SD) than bowers at Dreghorn (575 \pm 284 ; mean and SD), most likely because decorations are more abundant in the environment in Townsville than at Dreghorn (Doerr 2009b; N.R. Doerr, unpublished data).

Experiment 1: do males reject decorations placed upon their bowers?

\section{Townsville}

On 4 August 2006, I counted all red wires naturally present at bowers $(n=12)$. Males frequently steal red wires from 
other males' bowers (Doerr 2010), indicating these decorations attract the attention of competing males. From 5 to 17 August 2006, I conducted the following procedure at bowers (two bowers every 2 days). I removed all red wires and placed a new set on the main court of each bower; the main court contains the majority of decorations under natural conditions (Frith et al. 1996). I gave each male 125 red wires, which is $\approx 25 \%$ greater than the maximum displayed at the most highly decorated bower on 4 August 2006 (maximum $=102$; mean $=32 \pm 30$, SD). This ensured that all males within the population had the opportunity to display an enhanced signal during the experiment. Wires were $110 \mathrm{~mm}$ in length and $2-3 \mathrm{~mm}$ in diameter, similar in size to red wires naturally present on the courts of bowers (N.R. Doerr, unpublished data). Because the "red" wires naturally present at bowers can vary in color parameters, such as hue, chroma, and brightness (Endler et al. 2005; Endler and Day 2006), I attempted to re-create this variety in the experiment by identifying five types of red wires at bowers that were also available for purchase at local hardware or retail stores; this allowed me to buy experimental wires that were the same color and texture as the ones naturally present at bowers (Fig. 1). I gave males 25 wires of each of the five types; the numbers that males accepted did not differ by type (Friedman test, $X_{4}^{2}=0.469, n=12, P=0.976$ ). I also gave males five yellow wires of the same size. Great bowerbirds reject yellow decorations added to their bowers (Veselovsky 1978; Endler and Day 2006). If males rejected the yellow wires, this would indicate that they were not accepting decorations indiscriminately.

After 2 days, I counted the number of red and yellow wires remaining at bowers, removed them, and returned each male's original set. I categorized red and yellow wires as "accepted" if males had moved them from their original location and placed them less than $1 \mathrm{~m}$ from the bower. The majority of decorations are located less than $1 \mathrm{~m}$ from the bower under natural conditions (N.R. Doerr, unpublished data). Wires were "rejected" if males had not moved them from their original location or if males placed them greater than $1 \mathrm{~m}$ from the bower. During the experiment, two males had some of their wires stolen by other males, so I returned stolen wires to their original owners and monitored these males for an additional day. However, neighboring males returned to steal wires again, so I was unable to verify whether stolen wires were accepted or rejected. I classified stolen wires as rejected by test males, though including them did not alter the results.

On 17 August 2006, I supplemented males with red rings, following the same procedure as above. Red rings were the strongest correlate of mating success in 2003, and they are also frequently stolen (N.R. Doerr and L.B. Day, unpublished data). I gave each male 18 red rings, which is $\approx 25 \%$ greater
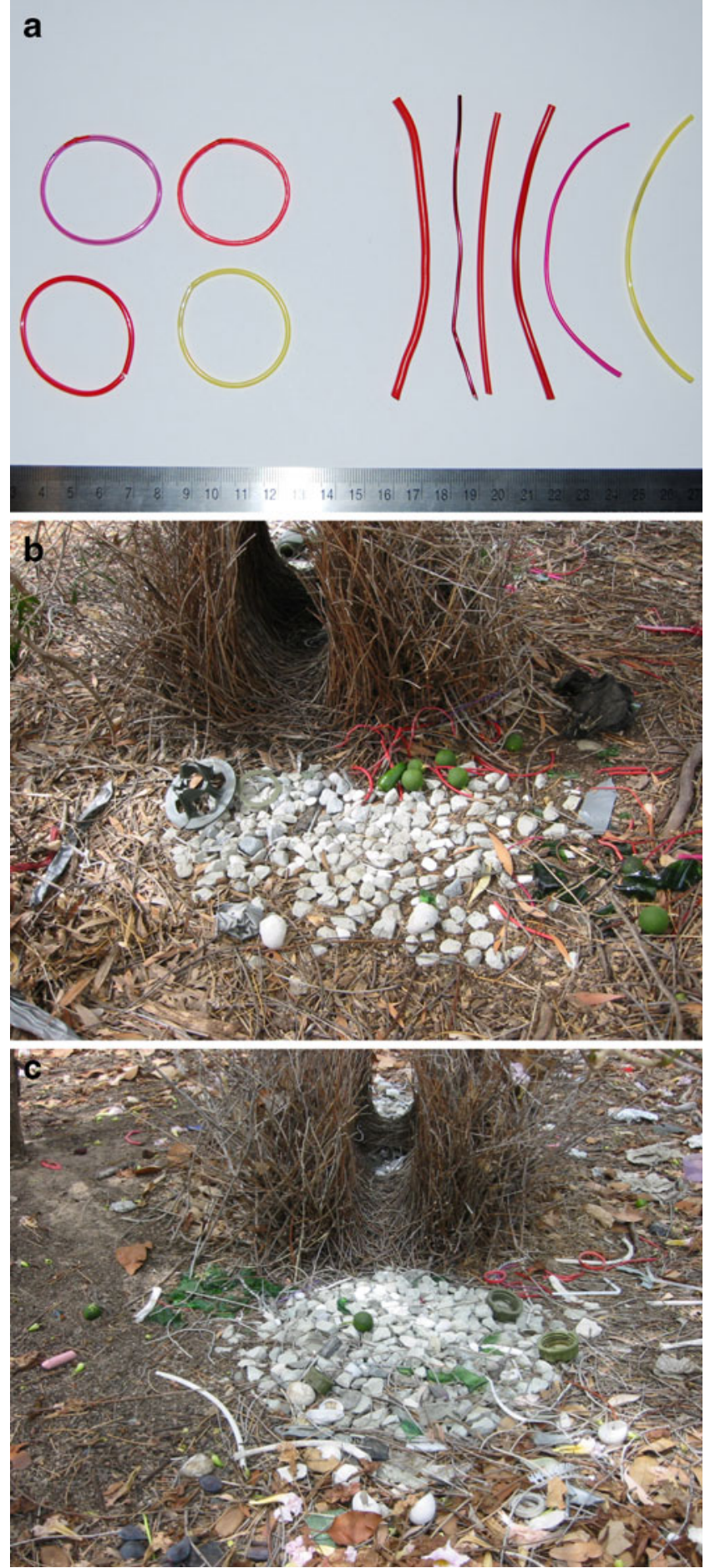

Fig. 1 The red wires and red rings used during the decoration supplementation experiments (a) and a sample of red wires and red rings naturally present at bowers $(\mathbf{b}, \mathbf{c})$

than the maximum displayed at the most highly decorated bower on 16 August 2006 (maximum $=15$; mean $=5 \pm 4, S D$ ). The red rings naturally present at bowers are hair ties and the plastic rings from bottlecaps, though I made rings by gluing together the ends of hollow, flexible wires to form rings 
similar in size to bottlecap rings (inner diameter, $40 \mathrm{~mm}$; outer diameter, $42 \mathrm{~mm}$; Fig. 1). Like red wires, the "red" rings naturally present at bowers can vary in color parameters, such as hue, chroma, and brightness (Endler et al. 2005; Endler and Day 2006), so I attempted to re-create this variety by giving males three types of red rings. Each male received six rings of each type, and the numbers males accepted did not differ by type (Friedman test, $X_{2}^{2}=0.692, n=12, P=$ 0.707). As a precautionary measure, I made a cut in each ring, so that the ring would break if the bird became entangled in it, though it should be noted that I have never observed this problem during 5 years of study of this species. I also gave males three yellow rings.

\section{Dreghorn}

From 6 to 12 September 2006, I repeated the above procedure at six bowers at Dreghorn. Dreghorn males naturally had very few red wires $(2.3 \pm 2.4, \mathrm{SD})$ and red rings $(0.3 \pm 0.5, \mathrm{SD})$ at their bowers, though they stole these items frequently (N.R. Doerr, unpublished data). To facilitate comparison with Townsville, I supplemented Dreghorn males with the same numbers that I did in Townsville: 125 red wires and 18 red rings. Three bowers were located on the periphery of the site, so some of the decorations that I classified as "rejected" may have been stolen by males that I did not monitor.

Experiment 2: how does decoration supplementation affect male marauding behaviors?

\section{Townsville}

From 5 to 30 October 2006, I monitored all activity at 14 bowers on Lavarack Barracks with motion-activated camcorders. I randomly assigned bower-owning males, all of whom had been color-banded, to one of two groups. For Group $1(n=$ 7, experimental), I removed all red wires and red rings from each bower and placed a new set of 125 red wires and 18 red rings (the same sets described in Experiment 1) on the main court of each bower. For Group 2 ( $n=7$, control), I counted all red wires and red rings at each bower, removed them, and replaced them with a new set equal to the numbers naturally present at that bower; each set was composed of approximately equal proportions of the different types of red wires and red rings described in Experiment 1. After 10 days, I removed experimental decorations, returned the original decorations, and gave all birds (Groups 1 and 2) a 5-day break. From 20 to 30 October 2006, I reversed treatments, so each male acted as a control for himself.

I visited bowers daily to replace lost decorations and to change tapes and batteries. I primarily visited bowers during nighttime hours (after 18:30 and before 05:30) to minimize disturbance to the birds. If I located a decoration that had been stolen from a supplemented bower, I recorded the identity of the thief and returned the decoration to its original owner. I returned decorations to ensure that males maintained an enhanced signal during the experiment. Though some of the decorations that I classified as stolen could have been rejected by test males before being "stolen" by another male, this possibility is unlikely because I often observed theft directly on the videotapes. In addition, the number of decorations that I observed males stealing on the videotapes was correlated with the numbers I recorded as stolen during bower visits (Spearman rank correlation, Townsville: $r_{\mathrm{s}}=0.664, n=14$, $P=0.010$; Dreghorn: $r_{\mathrm{s}}=0.854, n=14, P=0.0001$ ), suggesting I accurately recorded patterns of decoration theft. At the end of each 10-day period, I recorded the number of nonexperimental decorations, such as glass and plastic, which birds had stolen. Several males were located at the periphery of the study site and primarily interacted with off-site individuals. I visited off-site bowers daily to record the number of experimental decorations they had stolen and to return these decorations to their original owners. When watching tapes, I recorded the duration of each destructive event and the identity of the destroyer, though I could not always see his color bands. I also recorded the number of displays and copulations at each bower in order to examine whether decoration supplementation affected the mate choice decisions of females. Displays occurred when an individual arrived at the bower, and the bower owner performed stereotyped movements and vocalizations associated with courtship. Copulations occurred within the avenue of the bower and were clearly visible on tape.

To examine whether low-quality males experienced an increase in bower destruction during supplementation, I compared the change in destruction rate (supplemented minus control rate) with two variables that may be related to male competitive ability: the minimum number of years that each male had owned a bower and the number of red wires and red rings naturally present at the bower (Vellenga 1970; Borgia and Gore 1986; Madden 2002; Doerr 2010). I determined the minimum number of years that each male had owned a bower based on banding and behavioral data collected at the study site since 2000 . Males in their first year of ownership received a score of 1 . Because males had only been monitored in Townsville for 7 years, the maximum score was 7; this value is likely to be an underestimate because males can own bowers for at least 20 years (Frith and Frith 2004). The mean number of red wires and red rings at bowers was the average of counts performed on 3 and 19 October 2006. There was a strong correlation between the number of red wires and red rings at bowers (Spearman rank correlation: $r_{\mathrm{s}}=0.800, n=14, P=$ 0.001 ), so I combined these decoration types in the analysis. 


\section{Dreghorn}

From 5 November to 4 December 2006, I conducted the same procedure at 14 Dreghorn bowers. Because bowers were more difficult to access at Dreghorn, I visited bowers every other day to change tapes and batteries and to check for stolen items. In addition, I visited bowers during the day (5:00-12:00 and 14:00-18:30). Though only one bowerowning male was banded at this site, previous studies indicate that a single male maintains a bower for the duration of the breeding season (Frith and Frith 2004). Because males were not banded, I could not determine the minimum number of years that each male had owned a bower. In addition, males did not have enough red wires and red rings under natural conditions to enable a comparison of the numbers naturally present at bowers and the change in destruction rate during the experiment. Instead, I compared the change in destruction rate with the numbers of snail shells and human-made decorations naturally present at bowers. Dreghorn males frequently stole these items (Doerr 2009b), so they may reflect male quality or social status under natural conditions.

\section{Historical rates of bower destruction in Townsville}

In a previous study, I obtained data on rates of bower destruction in Townsville during the breeding seasons of 2002 (17 September to 18 December 2002, $n=17$ ) and 2003 (23 September to 15 December 2003, $n=15$ ), when bowers were monitored with motion-activated camcorders but otherwise contained natural numbers of decorations $(\mathrm{N}$. $\mathrm{R}$ Doerr, unpublished data). The camera equipment, setup, and monitoring procedure were the same as in the current study, except that a field assistant visited bowers every other day (instead of daily) to change tapes and batteries. In the current study, I used these data to determine whether the rates of bower destruction that males experienced during the above experiment differed from natural levels of destruction recorded at this site during previous years.

\section{Statistical analyses}

Due to the presence of outliers in the data on rates of bower destruction and decoration theft, I used non-parametric tests (Wilcoxon signed rank test, Mann-Whitney $U$ test, Spearman rank correlations corrected for ties) for all analyses. Under the null hypothesis, males should experience no difference in destruction rate, copulation rate, display rate, etc. between control and experimental treatments, and this satisfies the assumption of symmetry about the median of the Wilcoxon signed rank test. Because the study populations differed in their response to supplementation (change in destruction rate during supplementation: Townsville, $0.59 \pm 1.71$, SD; Dreg- horn, $-0.80 \pm 2.70$, Mann-Whitney $U$ test: $Z=-2.580, n_{1}=14$, $\left.n_{2}=14, P=0.010\right)$ and because I had more information about Townsville males (such as years of bower ownership) than Dreghorn males, I analyzed populations separately. However, I also sought to determine whether the average rate of occurrence of various behaviors, such as bower destruction and decoration theft, differed between sites, so I averaged behavioral rates over the course of the experiment (supplemented + control/2) for each population and compared these rates using Mann-Whitney $U$ tests. All tests are two-tailed and were performed with SPSS for Windows version 11.5 (SPSS Inc. 2002). A 5\% significance level was chosen, though test outcomes with $P$ values between 0.05 and 0.10 were reported according to the format: " $x$ was correlated, though not significantly, with $y$ " or "the mean of $x$ was higher, though not significantly, than $y$." Means are \pm SD.

\section{Results}

Experiment 1: do males reject decorations placed upon their bowers?

At both sites, males rejected the yellow wires and yellow rings, placing them greater than $1 \mathrm{~m}$ from the bower and beyond the periphery of the majority of bower decorations. At both sites, males accepted the majority of red wires and red rings, placing them less than $1 \mathrm{~m}$ from the bower (Table 1). There was no significant correlation between the numbers of decorations at bowers before supplementation and the numbers at bowers after supplementation at Townsville (Spearman rank correlation: red wire: $r_{\mathrm{s}}=$ 0.328, $n=12, P=0.298$; red ring: $r_{\mathrm{s}}=0.194, n=12, P=$ 0.545 ) or at Dreghorn (red wire: $r_{\mathrm{s}}=-0.522, n=6, P=0.288$; red ring: $\left.r_{\mathrm{s}}=-0.220, n=6, P=0.675\right)$.

Experiment 2: does decoration supplementation lead to an increase in bower destruction?

\section{Townsville}

The rate of bower destruction did not differ significantly between supplemented $(1.2 \pm 2.4 \mathrm{~min}$ of destruction per day) and control treatments $(0.6 \pm 1.7 \mathrm{~min}$ of destruction per day; Wilcoxon signed rank: $Z=-1.156, n=14, P=0.248$ ). Neither the destruction rate under control conditions nor the destruction rate during supplementation differed from destruction rates recorded during the breeding seasons of $2002(0.7 \pm 1.6 \mathrm{~min} /$ day, $n=18)$ and $2003(0.5 \pm 1.0 \mathrm{~min} /$ day, $n=15)$, when males were monitored with motion-activated camcorders but otherwise displayed natural numbers of decorations (control: Kruskal-Wallis test: $\chi_{2}^{2}=0.951, P=$ 0.622; supplement: $\chi_{2}{ }^{2}=1.674, P=0.433$ ). 
Table 1 The number of red wires and red rings naturally displayed at bowers before supplementation ("before") and the number males accepted after supplementation ("after") at Townsville and Dreghorn study sites

\begin{tabular}{|c|c|c|c|c|c|c|c|c|}
\hline & \multicolumn{4}{|c|}{ Townsville $(n=12)$} & \multicolumn{4}{|c|}{ Dreghorn $(n=6)$} \\
\hline & Before & After & $Z$ & $P$ & Before & After & $Z$ & $P$ \\
\hline Red wires & $32 \pm 30$ & $120 \pm 4$ & -3.061 & 0.002 & $2 \pm 2$ & $112 \pm 10$ & -2.201 & 0.028 \\
\hline Red rings & $5 \pm 4$ & $16 \pm 2$ & -3.062 & 0.002 & $0.3 \pm 0.5$ & $13 \pm 4$ & -2.214 & 0.027 \\
\hline
\end{tabular}

Results are from Wilcoxon signed rank tests; means are \pm SD

Males that had few red wires and red rings under natural conditions experienced a greater increase in destruction rate when supplemented than males that had many red wires and red rings (Spearman rank correlation: $r_{\mathrm{s}}=-0.757, n=14, P=$ 0.002 ; Fig. 2). There was a positive correlation, though not significant, between years of bower ownership and the change in destruction rate when supplemented $\left(r_{\mathrm{s}}=-0.462\right.$, $n=14, P=0.097)$. The destruction rate when supplemented was correlated with the destruction rate when displaying natural numbers of decorations $\left(r_{\mathrm{s}}=0.629, n=14, P=0.016\right)$.

Display rate did not differ between treatments (supplement, $2.53 \pm 2.82$ displays per day; control, $2.43 \pm 2.30$ displays per day; Wilcoxon signed rank: $Z=-1.099, n=$ $14, P=0.272$ ). The copulation rate was higher, though not significantly, when males were supplemented $(0.09 \pm 0.11$ copulations per day) than under control conditions $(0.02 \pm$ 0.08 copulations per day; $Z=-1.859, n=14, P=0.063$ ). Thirteen out of 16 copulations occurred at supplemented bowers, which suggests a significant female preference for supplemented bowers (sign test: $P=0.0213$ ).

\section{Dreghorn}

The rate of bower destruction that males experienced under control conditions ( $1.3 \pm 2.3 \mathrm{~min}$ of destruction per day) was

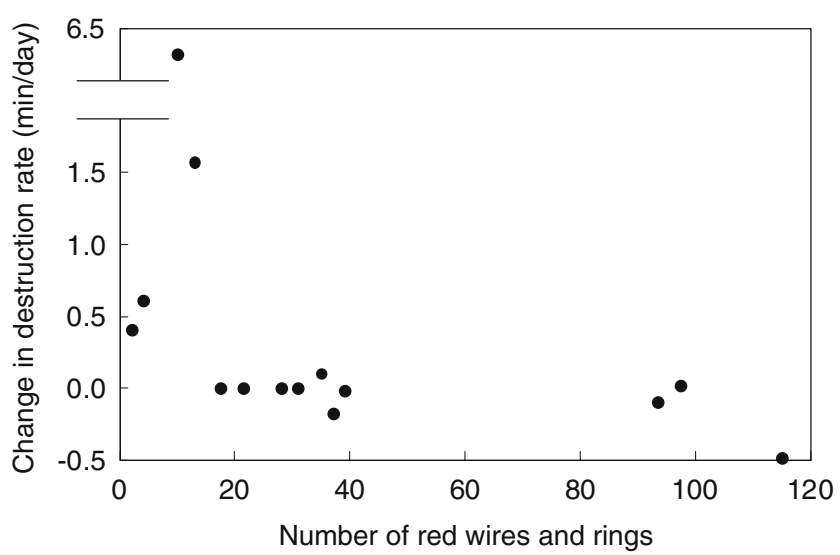

Fig. 2 The number of red wires and red rings naturally displayed at bowers in Townsville and the change in destruction rate (rate during supplementation-rate during control conditions; $\mathrm{min} /$ day) higher, though not significantly, than the rate they experienced when supplemented with decorations $(0.5 \pm 1.3 \mathrm{~min}$ of destruction per day; Wilcoxon signed rank: $Z=-1.883, n=$ $14, P=0.060$ ). There was no relationship between the change in destruction rate and the average number of human-made decorations or snail shells at bowers (Spearman rank correlation: human-made: $r_{\mathrm{s}}=-0.037, n=14, P=0.899$; snail shells: $\left.r_{\mathrm{s}}=-0.117, n=14, P=0.690\right)$. The destruction rate when supplemented was not significantly correlated with the destruction rate when displaying natural numbers of decorations $\left(r_{\mathrm{s}}=0.350, n=14, P=0.220\right)$.

Neither display rate nor copulation rate differed between treatments (display rate: supplement, $0.69 \pm 0.65$ displays per day; control, $0.85 \pm 0.64$ displays per day, Wilcoxon signed rank: $Z=-1.036, n=14, P=0.300$; copulation rate: supplement, $0.01 \pm 0.03$ copulations per day; control, $0.01 \pm 0.03$ copulations per day, $Z=-0.447, n=14, P=0.655)$. However, I only observed three copulations; two occurred at supplemented bowers.

What is the relationship between bower destruction and decoration theft?

At both sites, males that experienced high destruction rates during supplementation had more of their experimental

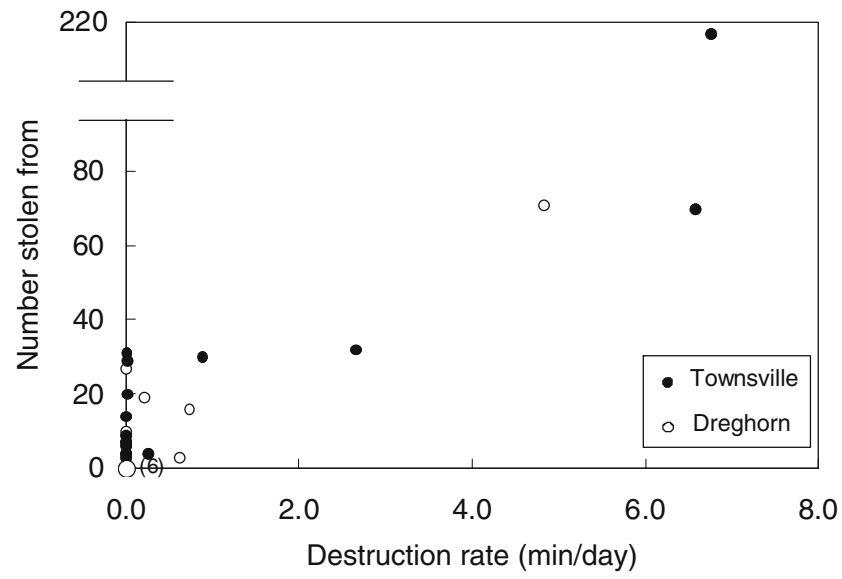

Fig. 3 The number of experimental decorations stolen from bowers and the rate at which bowers were destroyed during supplementation at Townsville and Dreghorn 
decorations stolen than males that experienced low destruction rates (Spearman rank correlation: Townsville: $r_{\mathrm{s}}=$ 0.764, $n=14, P=0.001$; Dreghorn: $r_{\mathrm{s}}=0.590, n=14, P=$ 0.026; Fig. 3).

\section{Townsville}

Males that had many of their experimental decorations stolen experienced a greater increase in destruction rate when supplemented than males that had few of their experimental decorations stolen $\left(r_{\mathrm{s}}=0.621, n=14, P=\right.$ $0.018)$. There was also an inverse correlation between the number of experimental red wires and red rings stolen from a male's bower and the number that he naturally displayed $\left(r_{\mathrm{s}}=-0.671, P=0.009\right.$; Fig. 4).

Males had more red wires and red rings stolen from their bowers when supplemented ( $34.0 \pm 55.7$ decorations) than under control conditions $(2.6 \pm 3.4$ decorations; Wilcoxon signed rank: $Z=-2.919, n=14, P=0.004)$. They also had more decorations stolen of all types (experimental+natural) when supplemented $(38.1 \pm 54.9$ decorations) than under control conditions (5.1 \pm 4.5 decorations; $Z=-2.733, n=14$, $P=0.006$ ).

\section{Dreghorn}

The change in destruction rate when supplemented was not significantly correlated with the number of experimental decorations stolen from bowers $\left(r_{\mathrm{s}}=0.341, n=14, P=\right.$ 0.232). The number of experimental red wires and red rings stolen from a male's bower was not correlated with the number of human-made decorations $\left(r_{\mathrm{s}}=-0.111, P=\right.$ $0.705)$ or snail shells $\left(r_{\mathrm{s}}=-0.247, P=0.395\right)$ naturally displayed at his bower. The number of decorations stolen from bowers during supplementation (experimen-

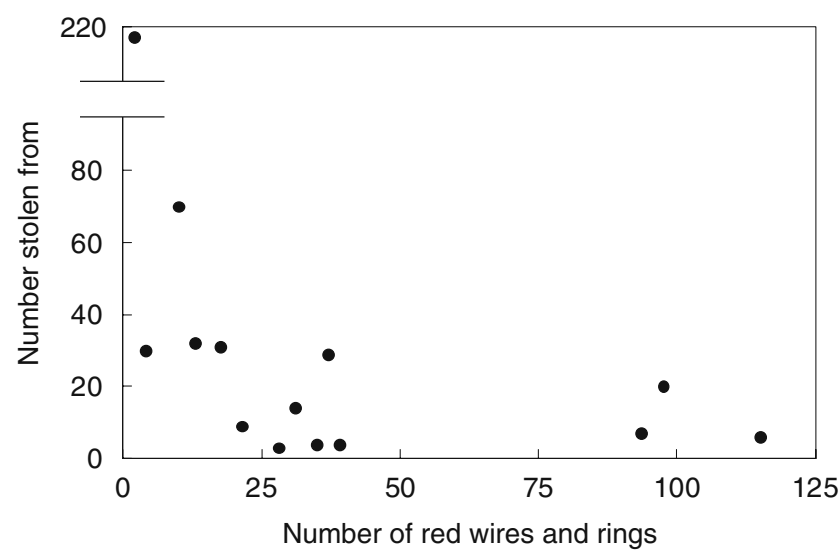

Fig. 4 The number of red wires and red rings naturally displayed at bowers in Townsville and the number that were stolen from bowers during supplementation tal + natural; $14.0 \pm 19.9$ decorations) was greater, though not significantly, than during control conditions (4.4 \pm 4.0 decorations; Wilcoxon signed rank: $Z=-1.682$, $n=14, P=0.093)$.

Did the behavioral variables differ between populations?

On average, Dreghorn males had a lower copulation rate (Dreghorn, $0.01 \pm 0.03$ copulations per day; Townsville, $0.06 \pm 0.07$ copulations per day; Mann-Whitney $U$ test: $Z=$ $\left.-2.105, n_{1}=14, n_{2}=14, P=0.035\right)$ and a lower display rate (Dreghorn, $0.78 \pm 0.58$ displays per day; Townsville, $2.48 \pm$ 2.34 displays per day; $Z=-2.580, P=0.002$ ) than Townsville males. They had fewer experimental decorations stolen from their bowers (Dreghorn, 11.2 \pm 19.2 decorations; Townsville, $34.0 \pm 55.7$ decorations; $Z=-2.310, P=0.021$ ) and fewer total decorations stolen (Dreghorn, 18.4 \pm 19.4 ; Townsville, 43.1 $\pm 52.9 ; Z=-2.069, P=0.039$ ). There was no difference in the average destruction rate between sites (Dreghorn, 0.85 $\pm 1.30 \mathrm{~min} /$ day; Townsville, $0.93 \pm$ $1.89 \mathrm{~min} /$ day; $Z=-0.968, P=0.333$ ).

\section{Discussion}

Male-male competition and honest signaling in Townsville

In Townsville, decoration numbers at bowers of the great bowerbird may function as honest signals of male social status or quality. When supplemented with red wires and red rings, males that naturally had fewer red wires and red rings at their bowers were more likely to experience an increase in bower destruction than males that naturally had many of these decoration types, and they were more likely to have their experimental decorations stolen by rivals. These results suggest that the numbers of decorations at bowers are an honest and repeatable signal of a male's ability to defend his display site from other males, and they confirm results from a previous study of the great bowerbird (Doerr 2010), in which decoration numbers were also negatively correlated with the rate at which males lost decorations to theft. A study in spotted bowerbirds found that males supplemented with Solanum berries, the best correlate of mating success, experienced an increase in bower destruction (Madden 2002), and two studies in satin bowerbirds found a positive correlation between the numbers of decorations at bowers and the male's ability to steal decorations from his neighbors (Borgia and Gore 1986; Wojcieszek et al. 2007). Thus, growing evidence supports the hypothesis that male-male competition influences the function and evolution of male mating signals in bowerbirds (Borgia et al. 1985) and other species (Berglund et al. 1996). 
However, there was no evidence that low-quality males chose to limit the size or conspicuousness of their mating signals to reduce interference from rivals. All males accepted the majority of red wires and red rings placed on their bowers, and there was no relationship between the numbers naturally present at bowers and the numbers males accepted during supplementation. Males often placed the experimental decorations in conspicuous locations, such as propped against the bower walls or hung within the avenues, and they presented them to females during courtship (N.R. Doerr, unpublished data). Thus, males incorporated the red wires and red rings into their displays, even though this led to increased bower destruction and decoration theft at certain bowers. Like bowerbirds, males of a number of species have fine-scale control over the size, conspicuousness, or timing of expression of their mating signals; but in contrast to my results, studies of dorsal darkening in tree lizards (Urosaurus ornatus) (Zucker 1994), crowing and comb size in junglefowl (Leonard and Horn 1995; Parker and Ligon 2007), and throat coloration in sticklebacks (Candolin 2000) have found that low-quality males limit their signal expression to avoid confronting superior males.

Why did male great bowerbirds accept the experimental decorations when doing so caused increased interference from rivals? The social control hypothesis predicts that males will choose to limit signal expression when the costs of dishonesty outweigh the benefits (Maynard Smith and Harper 1988; Guilford and Dawkins 1995). Bowerbirds differ from most species because their visual displays are external to their bodies, and this could alter the costs and benefits of exaggerated signaling to cheaters. Because males primarily direct their aggression towards the bower structure and its decorations, cheaters do not pay the high costs (e.g., injury, death) associated with physical fights; yet the high costs of physical fights are said to underlie the evolutionary stability of socially controlled signals in other species (Rohwer 1977; Berglund et al. 1996). In addition to reduced costs, cheaters may also reap substantial benefits: females mated more frequently at supplemented bowers. Finally, the social control hypothesis suggests that socially controlled signals will have low production costs (Rohwer 1977; Guilford and Dawkins 1995), yet research suggests that great bowerbirds face high time and energy costs when searching for decorations in the environment (Doerr 2009a). High acquisition costs could motivate males to accept decorations placed on their bowers and to steal them from other males. These factors suggest that honest sexual signaling occurs because males vary in the ability to acquire and retain decorations, not because low-quality males reject decorations they acquired cost-free. Indeed, males sometimes inherit bowers upon the death of the original owners, and they do not reject the decorations that are already present, even when they experience high levels of bower destruction and decoration theft (N.R. Doerr, unpublished data).

In contrast to my results, a study in spotted bowerbirds found a positive correlation between the numbers of Solanum berries naturally displayed at bowers and the numbers males accepted during supplementation, suggesting males had an awareness of their status in relation to other males (Madden 2002). These results may have differed from mine because Madden gave test berries to males in proportion to the numbers naturally present at their bowers, so males were not given an equal opportunity to create an enhanced display. In one experiment, males that naturally had fewer than 15 berries were presented with 30 test berries; but males that naturally had more than 15 berries were presented with double the number of berries naturally present at their bowers, for a total of $\approx 40-160$ test berries per bower (Madden 2002; Madden, personal communication). This could produce a positive correlation between the numbers of berries naturally present and the numbers males accepted during supplementation even if males did not reject any decorations. Nonetheless, male spotted bowerbirds did reject many of the decorations placed on their bowers and even when offered large numbers of berries at low cost chose not to take them (Madden 2002), so the relevance of the social control hypothesis to bowerbirds requires further research. A recent study in a crater-building cichlid (Cyathopharynx furcifer) found that males whose sand craters were experimentally enlarged chose to restore their craters to their original sizes, possibly to reduce aggression from rivals (Schaedelin and Taborsky 2006). These results suggest that it is possible for socially controlled signaling to occur in species that use non-bodily ornaments as mating signals. Interestingly, theft of sand by males has not been reported in this species (Karino 1996; Schaedelin and Taborsky 2006). Because sand is commonly available in the environment (Schaedelin and Taborsky 2006), this may favor the use of socially controlled signals over decoration theft.

Male-male competition and honest signaling at Dreghorn

In contrast to Townsville, there was no evidence of a relationship between male-male competition and the numbers of decorations at bowers at Dreghorn. When supplemented with decorations, males experienced less bower destruction, though not significantly $(P=0.06)$, and there was no relationship between the number of experimental decorations stolen from bowers and the number of snail shells and human-made objects naturally displayed at bowers. The main similarity between sites was that Dreghorn males accepted the majority of red wires and red rings added to their bowers, and males appeared to value the experimental decorations, placing them in prominent positions at the bower and presenting them to females during courtship (N.R. 
Doerr, unpublished data). In addition, the frequency with which Dreghorn experienced decoration theft was higher, though not significantly $(P=0.09)$, during supplementation than under control conditions.

A number of uncontrolled variables could explain differences between the sites, but three possibilities are of note. First, males may only respond vigorously to certain decoration types, such as those that are most attractive to females. Previous studies have found interpopulation differences in the decoration types preferred by female bowerbirds (Uy and Borgia 2000; Madden 2006), but I had no prior knowledge about the best correlates of mating success at Dreghorn. It is possible that males would have responded differently if I had supplemented them with a different type of decoration. Ecological factors could also explain the results. Dreghorn males had a lower copulation rate, lower display rate, and lower theft rate, and they received less rainfall during the experiment (rainfall: Dreghorn, $0 \mathrm{~mm}$; Townsville, $10 \mathrm{~mm}$; N.R. Doerr, unpublished data, Queensland Bureau of Meteorology, personal communication). If breeding conditions were substandard at Dreghorn, this could have altered patterns of male-male competition. However, the average rate of bower destruction did not differ between sites, suggesting ecological factors did not prohibit males from interacting.

Finally, the fitness payoffs to stealing and destruction may have differed between sites. Bowers at Dreghorn contained relatively few human-made objects under natural conditions, so the experimental decorations may have been especially prized by males, causing them to shift their investment from destruction to theft. This explanation is appealing because it accounts for the fact that Dreghorn males tended to experience more theft when supplemented, yet more destruction when displaying natural numbers of decorations. It could also explain why males placed the experimental decorations in prominent positions at the bower and presented them to females during courtship. Hunter and Dwyer (1997) suggest that males will invest more heavily in theft when decorations are rare at bowers, but more heavily in destruction when decorations are common. Though my results do not fully support this prediction-Townsville males had more decorations at their bowers yet they stole more decorations than Dreghorn males - they do suggest that males are attuned to the costs and benefits of different forms of male-male competition. Males of other species, such as guppies (Poecilia reticulata), have also been shown to adjust their competitive strategies in response to environmental variables, such as the density of rival males (Jirotkul 1999).

In sum, male-male competition appears to facilitate honest sexual signaling in a Townsville population of great bowerbirds, but there was no relationship between decoration numbers and honest sexual signaling in a second population at Dreghorn. Though previous studies have emphasized that bower destruction and decoration theft contribute to repeatable, individual differences in the numbers of decorations at bowers (Borgia et al. 1985; Madden 2002; Wojcieszek et al. 2007; Doerr 2010), my results suggest that the importance of male-male competition may vary across populations, and additional studies are needed to identify the social and environmental factors that contribute to this variation. Because males at both Townsville and Dreghorn accepted the majority of decorations added to their bowers, there was no clear evidence for the social control hypothesis at either site, and the lack of socially controlled signaling may have occurred because the external nature of bower decorations ensures that "cheaters" do not experience the high costs of physical fights, while "punishers" that steal decorations gain valuable resources for sexual display. Recent work has emphasized that signalers benefit from using non-bodily ornaments as signals because such signals can be abandoned to avoid predation (Schaedelin and Taborsky 2009); my results suggest that non-bodily ornaments could also be abandoned to avoid conspecifics, thus reducing the costs of signaling to cheaters. Interestingly, a number of studies have found that socially controlled signals occur among breeding males (Candolin 2000; Molles and Vehrencamp 2001; Parker and Ligon 2007), but theoretical work predicts that socially controlled signals are unlikely to occur in a mating context because the value of the resource (access to females) will outweigh the costs of fighting for it (Maynard Smith and Harper 1988; Pärt and Qvarnström 1997). A detailed assessment of the costs and benefits of exaggerated signaling, both to cheaters and the individuals that "punish" them, may help resolve the discrepancy between theory and empirical data.

Acknowledgements This study was supported with funding from the American Ornithologists' Union, a Frank M. Chapman Memorial Grant, and a National Science Foundation Graduate Research Fellowship. Thanks to the Smith family for permission to work at Dreghorn; to Allan McManus and the Australian Army for permission to work at Lavarack Barracks; and to Qantas Airlines for donating the videotapes. Lainy Day and John Endler ran the camcorder system during the breeding seasons of 2002 and 2003, and John and Lorna Endler kindly provided the use of a field vehicle during 2006. The School of Marine and Tropical Biology at James Cook University provided invaluable logistical support. Stephen Rothstein, Loren Merrill, and Amy Musante provided helpful comments on project design, and John Endler, Stephen Rothstein, Sam Sweet, Stephen Pruett-Jones, and Mark Hauber provided helpful comments on the manuscript.

Ethical standards My study complied with the current laws of Australia and the USA, and permissions were provided by Queensland Parks and Wildlife, the University of California Institutional Animal Care and Use Committee (IACUC), and the James Cook University Ethics Committee. 
Conflict of interest The author declares she has no conflict of interest.

Open Access This article is distributed under the terms of the Creative Commons Attribution Noncommercial License which permits any noncommercial use, distribution, and reproduction in any medium, provided the original author(s) and source are credited.

\section{References}

Berglund A, Bisazza A, Pilastro A (1996) Armaments and ornaments: an evolutionary explanation of traits of dual utility. Biol J Linn Soc 58:385-399

Borgia G (1985) Bower quality, number of decorations and mating success of male satin bowerbirds (Ptilonorhynchus violaceus): an experimental analysis. Anim Behav 33:266-271

Borgia G, Gore MA (1986) Feather stealing in the satin bowerbird (Ptilonorhynchus violaceus): male competition and the quality of display. Anim Behav 34:727-738

Borgia G, Pruett-Jones SG, Pruett-Jones MA (1985) The evolution of bower-building and the assessment of male quality. Z Tierpsychol 67:225-236

Candolin U (2000) Male-male competition ensures honest signaling of male parental ability in the three-spined stickleback (Gasterosteus aculeatus). Behav Ecol Sociobiol 49:57-61

Coleman SW, Patricelli GL, Borgia G (2004) Variable female preferences drive complex male displays. Nature 428:742-745

Doerr NR (2009a) Do male great bowerbirds (Ptilonorhynchus nuchalis) minimise the costs of acquiring bower decorations by reusing decorations acquired in previous breeding seasons? Emu 109:237-243

Doerr NR (2009b) Stealing rates in the great bowerbird (Ptilonorhynchus nuchalis): effects of the spatial arrangement of males and availability of decorations. Emu 109:230-236

Doerr NR (2010) Does decoration theft lead to an honest relationship between male quality and signal size in great bowerbirds? Anim Behav 79:747-755

Endler JA, Day LB (2006) Ornament colour selection, visual contrast and the shape of colour preference functions in great bowerbirds, Chlamydera nuchalis. Anim Behav 72:1405-1416

Endler JA, Westcott DA, Madden JR, Robson T (2005) Animal visual systems and the evolution of color patterns: sensory processing illuminates signal evolution. Evolution 59:1795-1818

Frith CB, Frith DW (2004) The bowerbirds: ptilonorhynchidae. Oxford University Press, Oxford

Frith CB, Frith DW, Wieneke J (1996) Dispersion, size and orientation of bowers of the great bowerbird Chlamydera nuchalis (Ptilonorhynchidae) in Townsville City, Tropical Queensland. Corella 20:45-55

Fugle GN, Rothstein SI, Osenberg CW, McGinley MA (1984) Signals of status in wintering white-crowned sparrows, Zonotrichia leucophrys gambelii. Anim Behav 32:86-93

Guilford T, Dawkins MS (1995) What are conventional signals? Anim Behav 49:1689-1695

Horn AG, Leonard ML, Weary DM (1995) Oxygen consumption during crowing by roosters: talk is cheap. Anim Behav 50:1171-1175

Hunter CP, Dwyer PD (1997) The value of objects to satin bowerbirds, Ptilonorhynchus violaceus. Emu 97:200-206

Jirotkul M (1999) Population density influences male-male competition in guppies. Anim Behav 58:1169-1175
Karino K (1996) Tactic for bower acquisition by male cichlids, Cyathopharynx furcifer, in Lake Tanganyika. Ichthyol Res 43:125-132

Leonard ML, Horn AG (1995) Crowing in relation to status in roosters. Anim Behav 49:1283-1290

Loffredo CA, Borgia G (1986) Male courtship vocalizations as cues for mate choice in the satin bowerbird (Ptilonorhynchus violaceus). Auk 103:189-195

Madden JR (2002) Bower decorations attract females but provoke other male spotted bowerbirds: bower-owners resolve this tradeoff. Proc R Soc Lond B 269:1347-1351

Madden JR (2003) Bower decorations are good predictors of mating success in the spotted bowerbird. Behav Ecol Sociobiol 53:269-277

Madden JR (2006) Interpopulation differences exhibited by spotted bowerbirds Chlamydera maculata across a suite of male traits and female preferences. Ibis 148:425-435

Martín J, Moreira PL, Lopez P (2007) Status-signalling chemical badges in male Iberian rock lizards. Funct Ecol 21:568-576

Maynard Smith J, Harper DGC (1988) The evolution of aggression: can selection generate variability? Phil Trans R Soc Lond B 319:557-570

Molles LE, Vehrencamp SL (2001) Songbird cheaters pay a retaliation cost: evidence for auditory conventional signals. Proc R Soc Lond B 268:2013-2019

Parker TH, Ligon JD (2007) Multiple aspects of condition influence a heritable sexual trait: a synthesis of the evidence for capture of genetic variance in red junglefowl. Biol J Linn Soc 92:651-660

Pärt T, Qvarnström A (1997) Badge size in collared flycatchers predicts outcome of male competition over territories. Anim Behav 54:893-899

Robson TE, Goldizen AW, Green DJ (2005) The multiple signals assessed by female satin bowerbirds: could they be used to narrow down females' choice of mates? Biol Lett 1:264-267

Rohwer S (1975) The social significance of avian winter plumage variability. Evolution 29:593-610

Rohwer S (1977) Status signaling in Harris sparrows: some experiments in deception. Behaviour 61:107-129

Schaedelin FC, Taborsky M (2006) Mating craters of Cyathopharynx furcifer (Cichlidae) are individually specific, extended phenotypes. Anim Behav 72:753-761

Schaedelin FC, Taborsky M (2009) Extended phenotypes as signals. Biol Rev 84:293-313

Senar JC, Camerino M (1998) Status signalling and the ability to recognize dominants: an experiment with Siskins (Carduelis spinus). Proc R Soc Lond B 265:1515-1520

Tibbetts EA, Dale J (2004) A socially enforced signal of quality in a paper wasp. Nature 432:218-222

Uy JAC, Borgia G (2000) Sexual selection drives rapid divergence in bowerbird display traits. Evolution 54:273-278

Vellenga RE (1970) Behaviour of the male satin bower-bird at the bower. Aust Bird Bander 8:3-11

Veselovsky Z (1978) On the biology and behaviour of the great grey bowerbird, Chlamydera nuchalis. J Ornithologie 119:74-90

Wojcieszek JM, Nicholls JA, Goldizen AW (2007) Stealing behavior and the maintenance of a visual display in the satin bowerbird. Behav Ecol 18:689-695

Zahavi A (1975) Mate selection - a selection for a handicap. J Theor Biol 53:205-214

Zucker N (1994) Social influence on the use of a modifiable status signal. Anim Behav 48:1317-1324 